\title{
A HIGIENIZAÇÃO DA ESCOLA PRIMÁRIA PORTUGUESA NO AMANHECER DO SÉCULO 20
}

\author{
Maria Manuela Rodrigues \\ Universidade de Lisboa, Portugal.
}

Resumo

O presente texto procura refletir sobre as preocupações higienizantes que, a partir dos finais do século 19, passaram a atuar no espaço escolar. De um modo mais específico, procurar-se-á acompanhar a transposição didática dos normativos legais ao território espacial das escolas primárias do Concelho do Barreiro, num período temporal que se estende até aos anos de 1920. Palavras-chave: higiene, escola primária, cultura escolar.

\section{THE PORTUGUESE ELEMENTARY SCHOOL HYGIENE AT THE TURN OF THE 20TH CENTURY}

Abstract

This paper seeks to reflect on the new hygiene concerns that from the late 19th century, act in school. In particular, it will try to follow the didactic transposition of the legal norms to the elementary schools spatial territory from Barreiro, in a time period that extends until the twenties of the 20th century.

Key-words: hygiene, elementary school, school culture.

\section{LA HIGIENIZAÇÃO DE LA ESCUELA PRIMARIA PORTUGUESA EN EL AMANECER DEL SIGLO 20}

\section{Resumen}

El presente texto pretende reflejar sobre las nuevas preocupaciones higienizantes que, a partir de los finales del siglo 19, actúan en el espacio escolar. De un modo más específico, se buscará acompañar la transposición didáctica de los normativos legais al territorio espacial de las escuelas primarias del municipio de Barreiro, en un período de tiempo que se extiende hasta los años 1920. Palabras-clave: higiene, escuela primaria, cultura escolar. 


\section{L'HYGIÈNE DANS L' ÉCOLE PRIMAIRE PORTUGAISE AU DÉBUT DU 20E SIÈCLE}

Résumé

Ce text vise à réfléchir sur les nouvelles préoccupations d'hygiène qui, dès la fin du $19 \mathrm{e}$ siècle, ont commence à agir dans l'espace de l'école. Plus spécifiquement, nous voulons accompagner la transposition didactique des normes juridiques au territoire des écoles primaires du comté de Barreiro, dans une période de temps qui s'étend jusqu'aux années vingt du 20e siècle.

Mots-clé: hygiène, école primaire, culture scolaire. 
m meados do século 19, as causas sociais assumem o protagonismo das preocupações da fragilidade civilizacional. Os olhares voltam-se para a cultura, para o saber, para os comportamentos e para os hábitos de vida das populações. A fraqueza física é claramente ligada a uma fraqueza do saber: o défice sanitário do operário e do camponês relacionam-se com a ignorância, pelo que as populações trabalhadoras têm de ser educadas, pois, da educação dependem o seu trabalho e a sua saúde (Vigarello, 2001). A moralização e o saber andam de mãos dadas para a transformação dos comportamentos. A instrução é o novo veículo da moderação dos excessos sejam eles de qualquer natureza, com vista à ordem social. A educação é convertida em caminho privilegiado para a disseminação da perspetiva higienista e higienizadora (Gondra, 2003). A divulgação de novos modos de viver e se comportar, fundados nos princípios da higiene concebida como uma ciência, foi um dos objetivos do ensino ministrado nas escolas, para além de, ao mesmo tempo, se envolver todo o espaço escolar e seus ocupantes sob o manto da medicina e da higiene. Assim, educação, civilidade e saúde figuraram como elementos indissociáveis da moralização da sociedade.

As descobertas de Pasteur vieram operar uma profunda transformação nas relações entre a sociedade e o Estado, o que conduziu a que a vida humana e as suas condições particulares adquirissem uma dimensão e um interesse públicos. Prevenir as doenças tornou-se uma questão essencial e os problemas de higiene passaram a ser problemas sociais. A instituição da vacina é a expressão visível do novo empenhamento estatal na vigilância e protecção da higiene pública: um exemplo disso passou-se em 1918, quando o subdelegado de saúde do Barreiro solicitou a intervenção da Câmara Municipal para que fossem afixados os editais alertando para o perigo da varíola, deu informação das pessoas vacinadas, requisitou mais vacinas e pediu para se aplicarem, de forma rigorosa, as multas designadas no regulamento de 23 de março de 1911, pois essa era a única forma de evitar a propagação de tão terrivel moléstia. O domínio da vacina aumentava a crença de que era possível extinguir as epidemias. Como observou Georges Vigarello (2001), a vacina constituiu o exemplo da tentativa de anular uma doença antes do seu aparecimento, protegendo o corpo contra toda a ocorrência, transformando-o a partir do interior, o que implicava pressionar todos os indivíduos a suportar um ataque físico para evitar a doença mas, também e principalmente, para evitar que a propagassem aos outros, ou seja, pretendia-se assim "afetar a carne de cada um no interesse de todos" ( $p$. 169).

A grande ameaça da decadência progressiva da espécie e a degenerescência toma conta dos debates: "a insistência numa degenerescência possível é uma forma de agitar um perigo massivo, de mobilizar consciências, de inventar solidariedades: aumentar a força das grandes mensagens coletivas numa sociedade em que se apaga cada vez mais o argumento religioso" (Ibid., p. 181). Aliás, Jean Maisonneuve (1988) estabelece uma associação curiosa ao considerar que a higiene pode ser considerada, num certo sentido, como "une sécularisation des lustrations religieuses dont elle conserve souvent le caractère impératif et minutieux" (p. 30). Podemos também encontrar certa paridade entre higiene e preceitos religiosos nas cerimónias católicas, dado que estas começam, muitas vezes, com a aspersão de água-benta, a fim de purificar a alma dos fiéis e de os livrar, a eles e ao espaço que ocupam, das tentações do demónio. Assim, com o fim de livrar da 
doença, o corpo e o espaço onde ele se move, há que recorrer a uma força dominadora dos indivíduos que lhes dita do exterior as normas e os deveres. Convertem-se as práticas de manutenção do corpo, surgem cuidados preventivos com vista ao crescimento e ao progresso.

Segundo António Gomes Ferreira (2004), nos finais do século 19, começou-se pela medicalização do espaço escolar e só depois se avançou para a medicalização do aluno. O principal objeto médico-pedagógico do discurso higienista foram as doenças contagiosas e a construção dos edifícios escolares; posteriormente, deslocou-se o alvo das atenções para as doenças produzidas pelo trabalho escolar e para as condições em que este se processava. O Estado, ao decretar a obrigatoriedade do ensino, tinha também de ser responsável pelas condições espaciais onde o mesmo se iria realizar. Se, por um lado, a reivindicação de uma higiene escolar se fundava na indispensabilidade de atender a condições adequadas ao desenvolvimento das crianças, por outro, ela surgia também como mais um campo de intervenção médica.

Nos finais do século 19, há uma tendência para colocar a ação pedagógica sob a fundamentação médica, em que o processo de aprendizagem passa a ser baseado no estudo do funcionamento do organismo humano. Nos séculos precedentes, a intervenção discursiva dos médicos incidia sobre o desenvolvimento físico da criança, porém, no século 19, ela alarga-se a espaços e dimensões educativas anteriormente menosprezadas. O discurso médico não se ficou, apenas, pela problemática das condições sanitárias das escolas, mas estendeu-se às condições e aos processos de aprendizagem, dando orientações sobre a distribuição do tempo, os métodos pedagógicos, o tipo e a sequência das atividades escolares. O desenvolvimento da criança, em contexto escolar, passa a ser alvo de análise no campo médico-pedagógico, nos finais do século 19 e princípios do século 20, com vista a uma escola organizada segundo uma pedagogia científica.

O discurso médico desse período acentuava o caráter doentio da escola, numa época em que a valorização social da escolaridade estava em ascensão, com o fim de tentar que a expansão do sistema escolar não adulterasse a saúde dos alunos e, também, de legitimar a intervenção médica no campo pedagógico, quer sobre os indivíduos, quer sobre a organização escolar e os processos a seguir no ensino (Ferreira, 2004). Assim, as estratégias do governo procuraram validar a regulamentação da normalidade, da conduta e das subjetividades baseando-se na ciência.

Carlota Boto (2012) encetou um estudo com base nos relatórios da inspeção de 1867 e os resultados da sua análise, em termos de situação higiénica, o total da amostra referia-se a 383 escolas, apontavam para a existência de $62,7 \%$ de escolas em condições consideradas satisfatórias, 32,9\% em condições pouco satisfatórias e apenas $4,4 \%$ foram caracterizadas insalubres. Quanto à qualidade da limpeza, a maior parte das escolas, de uma amostra de 369 escolas, estava no parâmetro satisfatório, o correspondente a 68\%, e apenas 3,3\% não apresentava qualquer limpeza. No que respeita a ventilação, os resultados indicavam que $61,5 \%$ das escolas teriam ventilação suficiente, 23,9\% deficiente e incómoda em $14,6 \%$ das escolas observadas, de um total de 390 escolas. A autora do trabalho chama a atenção para a dificuldade da generalização pela média, devido à profunda diversidade regional, e refere que os dados levam a crer que as 
escolas situadas em grandes centros urbanos eram privilegiadas em relação às existentes nas aldeias ou em povoados mais distantes.

A falta de condições higiénicas nas escolas é claramente assumida logo no início da portaria de 29 de dezembro de 1875, redigida nos seguintes termos: "constando pelos relatórios dos inspetores extraordinários de diversos circulos escolares e pelas informações de alguns governadores civis as péssimas condições higiénicas e pedagógicas em que se encontram muitas escolas de instrução primária". Para fazer face ao problema diagnosticado, os políticos atuam a legislar, mas de pouco terá servido na prática, porque, como refere Cândido de Figueiredo (1876), "para que os homens encaminhem a sociedade ao fim que por natureza lhe é destinado, não bastam leis e decretos" (p. 11).

As questões da higiene escolar fizeram a sua aparição nas últimas décadas do século 19. Em 15 de março de 1884, na Revista Escolar Portugueza (ano 1, n. 2), afirmava-se que "só modernamente tem sido estudada a aplicação da higiene à escola, e principalmente à primária" (p. 17) e, desde a escolha do edifício da escola até ao método utilizado, o professor teria de atender a todas as circunstâncias que pudessem contribuir para o desenvolvimento da criança que era confiada aos seus cuidados. A questão da responsabilidade do Estado pelo desenvolvimento físico e pela manutenção da saúde das crianças, que obrigava a frequentar as escolas durante uma parte da infância, estava patente no decreto n. 2, de 24 de dezembro de 1901:

O Estado haverá inspirado justificada confiança aos pais que procuram nas escolas, como santuário educativo de seus filhos, a máxima garantia e salvaguarda da saúde dessas crianças no periodo mais critico e contingente da existência? Responde-nos o aspecto doentio, e o crescente atrofiamento de raça que se observa na população que frequenta as nossas escolas públicas, presa futura d'esse flagelo - a tuberculose - que por todos os modos procuramos combater e dominar na sua marcha cruelmente invasora. (Boletim da Direcção Geral de Instrucção Publica. Anno de 1902, 1903, p. 2)

As apreciações críticas continuavam: "nem se compreende que uma lei, como a da obrigatoriedade do ensino, possa sacrificar a liberdade individual em nome dos interesses coletivos, impondo a aglomeração de crianças em locais que as condenam ao seu estiolamento físico" (Ibid., p. 5). Tornava-se inevitável um estudo aprofundado sobre a matéria:

Quer se considerem as condições relativas do terreno, a exposição da escola, a luz que recebe, o seu mobiliário, quer, mais particularmente, se considerem as crianças que a habitam, os seus trabalhos, as diversas posições, os exercicios, os recreios, as doenças, etc., tudo impõe um estudo e exige uma regulamentação especial. (Ibid., p. 3)

Reconhecia-se, finalmente, a necessidade urgente de se adequarem preceitos higiénicos apropriados aos espaços escolares.

No seguimento desta linha, o decreto n. 4, de 19 de setembro de 1902, que regulamenta o decreto $n$. 8 , de 24 de dezembro de 1901 - reforma do ensino primário, estabelecia que uma das competências do inspetor sanitário seria a inspeção na própria escola, no início de cada ano escolar, de todas as crianças que entrassem pela primeira 
vez, enquanto que os outros alunos seriam alvo de uma inspeção mais superficial e ligeira. No caso de um aluno contrair tinha ou pelada, só poderia regressar à escola "depois de feito o tratamento e com um penso metódico, devendo ser prevenidos os restantes alunos de que não deverão fazer uso de qualquer peça de vestuário que pertencer ao contaminado" (decreto n. 4, 19 set., 1902, art. 374, $3^{\circ}$ ).

Se o inspetor sanitário reconhecesse sintomas de doença transmissível em algum aluno, este seria imediatamente entregue à família, acompanhado de um boletim no qual se indicariam os cuidados a ter para evitar possíveis contágios, informando-a de que o aluno não poderia ser recebido na escola sem que tivesse tomado "um ou mais banhos gerais" e desinfetado todo o seu vestuário, livros, cadernos e outros objetos de uso pessoal; "a sala da classe do aluno será imediatamente desinfetada, durante a suspensão dos trabalhos escolares, pela desinfeção pública"1 (Ibid., $4^{\circ}$ ). A duração do impedimento à frequência da escola, no caso de afeção transmissível, variava consoante a doença: "variola, escarlatina e difteria, quarenta dias; erisipela, coqueluche e febre tifóide, trinta dias depois da cura; varicela, sarampo e trazorelho, dezasseis dias" (Ibid., 6º. 0 impedimento da entrada na escola, detetado este tipo de afeções, alargava-se a todos os que coabitassem com o aluno afetado e não só o inspetor sanitário teria autoridade para fazer esta proibição, como também o próprio professor.

Na portaria de 5 de abril de 1910, destinada a esclarecer os critérios que deviam ser seguidos pelas autoridades escolares na qualificação do serviço dos professores das escolas primárias, havia uma parte intitulada Higiene escolar, que apelava à atenção do subinspetor para que avaliasse a forma como esta era posta em prática pelo docente. Apesar de se reconhecer que "o professor não dispõe de meios para modificar as condições defeituosas, sob o aspecto higiénico, de um edifício escolar, mas pode manter a casa da escola e suas dependências sempre em ordem"; o professor podia também cuidar do "preciso asseio", "arejar a sala de aula quando os alunos ali não estejam" e "vigiar pela conservação e bom estado de edifício e do mobiliário" (Ministério dos Negócios do Reino, portaria de 5 de abril de 1910).

Neste ponto, crê-se que esta competência atribuída aos professores já fosse assumida nessa altura como um hábito inerente às suas funções, pelo que é desta forma que se justifica o ofício dirigido à Câmara Municipal do Barreiro, em julho de 1901, pelo professor oficial da escola do sexo masculino da vila, requisitando uma barrica com desinfetantes para a escola a seu cargo (AMB, 31 jul., 1901). Os aspetos da higiene escolar a observar aquando da avaliação do desempenho dos professores, não se ficavam apenas pelos espaços, porquanto, "não deve merecer ao sub-inspector menor atenção a limpeza dos alunos" (Ministério dos Negócios do Reino, Portaria de 5 de abril de 1910). Cabia ao professor estimular nos alunos hábitos de higiene pessoal: "o professor que se descuida de criar estes hábitos de asseio e higiene falta a um dos seus deveres mais imperiosos" (Ibid.). Reconhecia-se de antemão que os alunos "são

\footnotetext{
${ }^{1}$ No final de 1913 seria atendido o pedido feito à Câmara Municipal pelo subdelegado de saúde do Barreiro para desinfeção da escola do sexo masculino do Lavradio, "onde esteve doente o marido da respetiva professora" (AMB, 24 dez., 1913). 
ordinariamente pobres", mas tal não devia ser impeditivo para que aparecessem na escola "bem lavados, com os dentes e cabelos limpos, e as unhas cortadas e asseadas" (lbid.)

No $1^{\circ}$ Congresso Pedagógico de Instrução Primária e Popular, realizado em abril de 1908 e promovido pela Liga Nacional de Instrução, é feita acérrima crítica à legislação vigente sobre higiene no programa do ensino primário: "no do primeiro grau, nem a mais leve referência se encontra à higiene" (Nazareth, 1909, p. 131), mas, em contrapartida, este mesmo programa exigia que, em matéria de aves domésticas, os alunos tivessem conhecimentos da "sua alimentação e engorda, principais doenças que as atacam, meios de as evitar e remédios com que se devem combater, não esquecendo os cuidados que reclama a criação dos bichos de seda e das abelhas" (Ibid.), pelo que, "segundo o critério do legislador de 1902, é muito mais importante, para a prosperidade e engrandecimento do país, a saúde e engorda das galinhas e dos perus, o bem estar do bicho da seda e das abelhas, do que a conservação integral e robustecimento dos seus habitantes" (Ibid.).

Por outro lado, "para contrapor a esta penúria máxima de educação higiénica no primeiro grau de instrução primária, aparece-nos, pomposamente ataviado, o programa para o 2..$^{\circ}$ grau a impor aos alunos vastos conhecimentos sobre variados ramos da higiene" (Ibid.); o problema aqui colocava-se na falta de formação dos docentes para ministrarem tais ensinamentos, a que acrescia o facto, que era visto como curioso, do programa aprovado por decreto de 18 de outubro de 1902, para uso das escolas de instrução primária do $2^{\circ} \mathrm{grau}$, abranger matérias que não estavam incluídas no programa das escolas normais.

Neste Congresso Pedagógico foram também apresentados os moldes em que se deveria processar o ensino da higiene nas escolas normais, nas escolas primárias de adultos e nas escolas primárias de crianças e é sobre estas últimas que nos iremos debruçar um pouco.

A higiene devia ser ensinada às crianças, desde que entrassem na escola até que saíssem, pela utilização, sempre que possível, do exemplo, reduzindo-se os ensinamentos teóricos apenas ao indispensável. A metodologia prescrita poderia resumirse ao seguinte:

Assim, para exemplificar, a falta de limpeza das mãos de um aluno, um objeto apanhado do chão, que viu meter na boca, serão pretextos para fazer compreender aos discípulos quanto é perigoso para a saúde comer seja o que for, sem lavar previamente as mãos, e, por associação, fácil é mostrar-Ihes que não devem mastigar fruta sem a descascar ou lavar; e dada em termos comezinhos, a razão da regra, expostos os motivos por que se deve proceder de certo modo e não de outro, o professor curará de a fazer respeitar, na prática, aventando hipóteses que exijam a sua aplicação. Deste modo conseguirá, não só gravar indelevelmente os preceitos higiénicos na mente das crianças, mas também, o que é de capital importância, erigir a execução deles em hábitos que sejam necessidades. (Ibid., p. 136) 
O professor, sempre orientado por estas normas, não deveria perder a oportunidade de ministrar aos seus alunos noções muito elementares sobre as vantagens e processos de limpeza e asseio do corpo e da habitação, sobre meios de defesa contra as doenças infecciosas, sobre alimentação e vestuário, para além de ensinar alguns rudimentos de primeiros socorros em caso de acidente. Em qualquer destes pontos, aquilo que o professor ensinasse devia estar adaptado às condições do meio local e social, "procurando de preferência, quanto puder, antes transformar do que destruir os hábitos tradicionais e reservando a condenação formal só para os erros prejudiciais que tiverem voga na região" (Nazareth, 1909, p. 137).

Os conselhos de higiene impunham uma nova peleja contra as negligências e as rusticidades, pois, um novo perigo espreitava a cada esquina e era importante veicular as normas de higiene pela escola. Neste sentido, uns anos mais tarde, no artigo Educação e higiene, publicado na primeira página de um jornal do Barreiro, passava a mensagem de que a única forma de educar o povo era através das crianças:

Sem educação não pode haver higiene. E sem higiene não pode haver vitalidade! Precisamos, pois, de procurar a forma de educar o nosso povo, principalmente o nosso minúsculo povo, o adulto povo de amanhã, visto que educar o adulto de hoje é tarefa senão impossível, pelo menos muito difícil. (Éco do Barreiro, 15 mar., 1925)

Apesar de se reconhecer que se deveria incutir nas crianças os bons hábitos de higiene, havia o problema de apenas um número reduzido de professores estar sensibilizado para a questão e, por outro lado, também se antevia que os resultados não fossem positivos devido aos exemplos que aquelas encontravam em casa:

Se nas nossas escolas primárias, em geral, apenas se ensina $\circ \mathrm{ABC}$, excepção feita a um ou outro professor, que aos seus alunos explica a maneira de se conduzirem perante a família e os estranhos, sendo essas mesmas excepcionais explicações de resultados improfícuos em presença dos hábitos e costumes opostos que o aluno, na maior parte dos casos, observa no seio da família? (Ibid.)

A solução proposta passava pela criação de escolas de educação em cada uma das diversas coletividades da terra: deveriam realizar-se, periodicamente, umas quantas conferências educativas, numa sala de cada coletividade disponibilizada para o efeito, a que seriam obrigados a assistir os filhos dos sócios, e seria facultada a entrada a todas as outras crianças e mesmo aos adultos que quisessem. Com estas iniciativas, e com o que nas escolas era ensinado, esperavam que a situação que se vivia fosse alterada.

O problema da falta de higiene na vila era um problema antigo, pois já em 23 de agosto de 1917 essa observação havia sido feita pelo subdelegado de saúde, "sobre as más condições higiénicas do Concelho, por falta de asseio" (AMB). A 7 de fevereiro de 1918, o subdelegado de saúde volta a dirigir-se à Câmara pedindo para que fossem removidos vários focos de infeção existentes na praia que prejudicavam a saúde pública e, ainda, para se ordenar à Polícia e à Guarda Republicana, que impedissem o despejo, para as ruas da vila e para a praia, dos lixos que deviam ser recolhidos nas carroças da limpeza. No verão desse mesmo ano, um dos vogais informava "que se acham em mau 
estado de asseio, quase todas as ruas da vila, o que é perigoso para a saúde pública, principalmente nesta quadra do ano, em que abunda já as pessoas atacadas de varíola", e, também, lembrava a conveniência da publicação de um edital recomendando aos habitantes "para que não deitassem para a rua quaisquer líquidos ou lixos que possam concorrer para o desenvolvimento de doenças" (AMB).

A escola era entendida como o local adequado para formação de cidadãos, mas também era olhada, pelo discurso médico, como um local que roubava a saúde física e psicológica dos alunos, atendendo às condições em que se fazia a escolarização (Ferreira, 2003). O discurso médico, ao acentuar o caráter doentio da escola, tinha em vista obstar a que a generalização da escolaridade se fizesse a qualquer preço, pelo que denunciava as condições a que os alunos estavam sujeitos, com o fim de impelir as autoridades públicas a modificarem o que prejudicava a saúde dos alunos. Vejamos alguns desses exemplos.

Em 1912, no $3^{\circ}$ Congresso Pedagógico, Nicolau Bettencourt apresentou uma tese sobre a prevenção das doenças contagiosas, na qual apontava as condições de salubridade do local, situação do edifício escolar, cubagem, exposição, iluminação, temperatura, ventilação, mobiliário, bem como os lavabos e as retretes, como podendo ter ação indireta e influir, em maior ou menor grau, na propagação das doenças contagiosas. Dizia que as leis portuguesas e regulamentos estavam de acordo com o que se legislava também noutros países, "simplesmente entre nós esses preceitos são quase inteiramente letra morta - porque não há recursos nem pessoal” (Bettencourt, 1912, p. 138). Criticava o facto de todas as funções da inspeção sanitária serem confiadas aos subdelegados de saúde, em vez de se criar um corpo privativo de funcionários de saúde destinados apenas àquele fim, suficientemente remunerados para poderem dispensar a clínica.

Os subdelegados de saúde eram facultativos municipais a quem se entregavam todas as funções de higiene e policiamento sanitário no concelho, em troca de uma exígua remuneração que ia de 50 a 150 mil réis anuais: "toda esta enorme complicação de serviços de que a inspecção escolar constitui apenas uma parcela mínima, está entregue a um médico que tem de ser, antes de tudo e acima de tudo, um clínico, porque só a clínica lhe pode garantir os proventos" (Ibid., p. 138). Tecia algumas considerações críticas sobre o que estava legislado sobre doenças contagiosas e os impedimentos de frequência escolar decorrentes daquelas, devido ao seu incumprimento na realidade. Ressaltava, no entanto, um aspeto positivo na legislação do ensino primário: a obrigatoriedade do ensino da higiene escolar nas escolas normais, pois, "na verdade o professor pode e deve ser um excelente auxiliar do inspector sanitário escolar desde que um ensino cuidadoso e bem orientado lhe dê os conhecimentos essenciais deste ramo da higiene" (lbid., p. 141).

No mesmo Congresso, outro relator, Artur Fernando Rocha, apresentou uma comunicação intitulada Doenças contraídas na escola e seus remédios, na qual evidenciava as doenças que resultavam da insuficiente oxigenação do sangue do estudante, devido não só às "abomináveis condições de instalação", mas também às "atitudes viciosas escolares", porque provocavam ou contribuíam para assimetrias do 
tórax, "verdadeiras deformações impeditivas do regular trabalho pulmonar, abatendo, comprometendo a função respiratória, por excelência nutritiva" (Rocha, 1912, p. 133).

A situação, o arejamento, a iluminação e o aquecimento da escola eram responsáveis por uma parte dos problemas de saúde ${ }^{2}$, mas eram também chamados à responsabilidade, nesta matéria, os professores que não deviam consentir outra posição nos alunos que não fosse a de "tronco direito em extensão natural" (lbid.). As suas observações respeitavam aos liceus, mas isso não invalida que não se possa fazer a extensão das suas ideias ao ensino primário, onde as condições físicas de instalação das salas de aula eram ainda bem piores e onde se iniciava o aparecimento dos vícios de postura. Outros aspetos foram por ele também alvo de atenção na tese apresentada: a digestão e seus problemas: infeções do aparelho digestivo poderiam ter origem no "costume inveterado em todos os alunos de tudo meterem na boca e roerem: lápis, papel, livros, correias destes, unhas, etc." e a "ingestão, por copo único, de águas principalmente, contidas em vasilhas mal cuidadas e, tantas vezes, de origens duvidosas" (Ibid., p. 134), a visão, pois, na sua opinião este é dos órgãos dos sentidos aquele que facilmente se altera nas escolas, e, por fim, a questão do mobiliário escolar, que dizia ter uma grande influência na produção de alguns males da infância e da adolescência.

Pedro José Ferreira, no discurso proferido por ocasião desse mesmo $3^{\circ}$ Congresso Pedagógico, salientava as más condições das escolas: "em geral nas nossas escolas não há ar, luz, sol, água, não há espaço para os exercícios físicos e exposições aos meios, são a negação da higiene; as crianças perdem nelas a pouca saúde que trazem", pelo que "não teremos cidadãos robustos, homens de ação" e "uma escola sem um pequeno jardim, sem um ginásio adequado, sem um terreiro para jogos e recreios, tornar-se há para as infelizes crianças, em vez de escola, um meio deformante" (Ferreira, 1913, p. 161).

Mas não era somente nos congressos pedagógicos que estas questões eram levantadas. Em 1913, Armando Pereira, na sua dissertação intitulada A higiene nas escolas primárias do Porto, apresentada à Faculdade de Medicina do Porto, defendia que a limpeza e conservação da escola, quer no exterior quer no interior do edifício, era deveras importante,

não só a bem da higiene, mas também como ensinamento às crianças que a frequentam, pois assim se habituarão a viver numa atmosfera de asseio, ao mesmo tempo que se provoca da sua parte um incitamento assaz

\footnotetext{
2 Segundo a Inspecção Geral de Sanidade Escolar, os médicos escolares constataram ter havido um aumento da percentagem de crianças débeis e portadoras de lesões gânglio-pulmonares específicas nas escolas primárias oficiais de ensino geral em Lisboa nos dois anos anteriores a 1920 (portaria n. 2.433, de 14 de setembro de 1920, Diário do Governo, I série, n. 182, 15 de setembro de 1920). Para fazer face à este problema, e atendendo a que "as escolas ao ar livre, organizadas em harmonia com os princípios fundamentais da higiene, resolvem eficazmente uma parte do problema" (Ibid.), a Inspeção Geral da Sanidade Escolar tinha a incumbência de promover a instalação e o funcionamento de uma ou mais escolas ao ar livre na cidade de Lisboa, para as crianças recrutadas pelos médicos escolares entre as que frequentavam as escolas primárias de ensino geral. Em 1923 é cedida, à Inspeção-Geral de Sanidade Escolar, a cêrca do Palácio das Necessidades que estava desaproveitada, juntamente com os anexos (dependências rurais e urbanas), para a instalação de uma escola ao ar livre. Essa cerca, e respectivos anexos, situava-se num "bairro pobre e populoso de Lisboa" (decreto n. 8.832, 17 de maio de 1923, Diário do Govêrno, I série, n. 103, 17 de maio de 1923) com "excepcionais condições de arborização, jardinagem e pureza de ares", pelo que "se presta a combater a ação deletéria que os grandes meios exercem sobre as populações infantis".
} 
proveitoso para que nas suas casas obriguem pelo seu exemplo, os pais, por vezes duma rudeza inqualificável, a respeitar os princípios basilares da mais elementar higiene. (Pereira, 1913, p. 18)

Ele atribuía a miopia, que se observava em muitos adultos, a uma distribuição defeituosa da luz nas salas de aula que eles frequentaram quando eram crianças. A importância da luz não se restringia, apenas, à função visual, mas também devia ser entendida como poderoso anti-séptico. Para este autor, a iluminação natural preferida era a unilateral esquerda, porque, desta forma, na ocasião em que as crianças escrevem, a sombra do braço e da pena ou lápis não se projeta sobre o papel; a luz quando entra pela direita torna a escrita mais difícil e obriga a um maior esforço de atenção, ao mesmo tempo que prejudica os órgãos visuais. Relativamente à questão da ventilação do recinto das aulas, Armando Pereira chamava a atenção para a necessidade de se manter o ar sempre puro, na medida do possível, de modo a evitar os inconvenientes de uma atmosfera viciada que para além de ser prejudicial para os adultos ainda o era mais para as crianças, porque apresentavam condições de recetividade mais favoráveis e em maior número para as doenças: "quem, como nós, entrou em tantas escolas sempre em pleno funcionamento, não mais esquece esse cheiro desagradável, que nas salas de aula se desenvolve, quando não são suficientemente ventiladas" (Pereira, 1913, p. 32).

Para a ventilação adequada da sala de aula preconizava a existência de bandeiras móveis na parte superior das janelas e das portas e, na parte oposta àquelas, abrir-se-iam orifícios, junto ao pavimento das salas, que se obturariam sempre que se quisesse e por onde se regularia a entrada de ar. Durante o intervalo dos trabalhos escolares, as portas e as janelas deviam ser amplamente abertas; contudo, refere que em algumas escolas da cidade do Porto isso não sucedia, porque as escolas não possuíam recreios onde as crianças pudessem estar nos períodos de descanso, sendo obrigadas a brincar dentro das próprias salas, "saturando o ar de produtos de intoxicação - exalações pulmonares e cutâneas, e de poeiras que levantam com seus folguedos" (Ibid., p. 33).

$\mathrm{O}$ arejamento do passado que privilegiava a difusão do perfume para mitigar os odores é, agora, substituído pelo princípio de que o ar deve circular. A acumulação de pessoas em locais confinados ocasionava a falta de elasticidade do ar restituído pela proximidade e demasia de pulmões, a que se acrescia o excesso de calor, de humidade e dos odores provocados. A importância da circulação do ar nos espaços coletivos assumia especial cuidado para a saúde de todos. Esta noção era tão importante que Agostinho de Campos (1922) escrevia, ironicamente, "as aglomerações humanas favorecem a difusão da epidemia, e, portanto, não se abrem as escolas. Antes burro vivo, que sábio morto" ( $p$. 168).

Outro aspeto digno de nota refere-se à questão dos vestiários, à entrada das escolas, onde os alunos colocavam os chapéus, os guarda-chuvas, as cestas com o lanche e os casacos de agasalho. Apesar de recomendados na época, Armando Pereira (1913) constatava a sua quase inexistência, pelo que as crianças levavam os seus pertences para as carteiras ou, então, penduravam-nos, de forma indistinta, nuns cabides espalhados pelos corredores ou nas próprias salas, o que acarretava certa promiscuidade, pois, "um aluno, cujo couro cabeludo seja presa de qualquer processo mórbido essencialmente contagioso, ou cujo cabelo albergue parasitas, poderá transmitir 
a sua doença a um camarada hígido ou povoar-lhe a cabeça limpa, desde que ambos se utilizem indistintamente do mesmo cabide" (Ibid., p. 39).

No respeitante a mictórios e latrinas, preconizava a sua colocação num extremo do edifício e em comunicação direta com o recreio descoberto, de forma a evitar a propagação de exalações indesejáveis e a entrada das crianças no edifício escolar nos tempos de recreio quando quisessem utilizar-se deles. As latrinas deviam ter uma bacia de porcelana, de forma aproximada a um irregular tronco de cone, de base elíptica, cujas dimensões estariam de acordo com a estatura das crianças, pelo que dentro da mesma escola deveria haver latrinas de vários tamanhos; relativamente às já existentes, "as velhas latrinas em caixão, com buraco circular, sem bacia, ou com esta sem sifão, ou com um rudimento de válvula, que precedeu o aparecimento daquele, e que tanto abundam no Porto, devem ser completamente substituídas" (Pereira, 1913, p. 45).

Ora, o sifão é um dispositivo particular que triunfa na nova instrumentalização do espaço sanitário, sendo o símbolo das práticas hidráulicas do final do século 19: "o sifão ilustra os dois objetivos dos arranjos interiores: o reforço dos débitos domésticos por um lado, o isolamento de cada ponto de água, por outro" (Vigarello, 2001, p. 217). Com um contorno encurvado em forma de cotovelo, o sifão é colocado sob o fundo das tinas, das cubas e das pias de despejo, detendo a possibilidade de comunicação com as matérias perigosas; assim, a sua eficácia sanitária reside no facto dele preservar o corpo isolandoo das matérias.

No início do século 20, a municipalidade barreirense resolve aplicar um novo sistema de esgotos nas escolas primárias da vila, para substituir o obsoleto sistema de baldes. A Câmara Municipal, com o objetivo de dotar os edifícios escolares de ensino primário da vila "dum melhoramento importante para a boa higiene dos alunos das referidas escolas", resolveu demolir as retretes existentes, onde os dejetos se depositavam em baldes que ao findar os trabalhos escolares eram vasados nas carroças da limpeza, e mandou fazer um novo projeto de retretes em que os dejetos fossem lançados diretamente numas fossas do sistema Mouras (Câmara Municipal do Barreiro, 30 abr., 1902). Aquele sistema representava um grande avanço relativamente ao anterior, permitindo a resolução de dois problemas: "primeiro a liquefação dos dejetos, facilitando assim a sua canalização e condução para qualquer ponto; segundo fazendo desaparecer por completo os gases, que em outros sistemas, se desenvolviam por ocasião da decomposição das matérias fecais" (Ibid.)

Por uma questão de garantia, foram projetadas duas fossas contíguas: uma para receber diretamente as matérias fecais e a outra, com metade da volumetria, para receber as urinas e purificar as águas da primeira fossa. As novas retretes foram projetadas por cima dessas fossas, sendo cinco retretes e um urinol com quatro compartimentos para a escola do sexo masculino e seis retretes para a escola do sexo feminino. A concluir a memória descritiva do projeto, o condutor de obras públicas que a assina informa que "o despejo da segunda fossa é feito diretamente para o rio em tubagem de grés" (Ibid.). Esta questão dos esgotos num sistema de ramais ocultos no interior do solo remete-nos para o funcionamento interno do nosso próprio corpo, mais concretamente da rede sanguínea: "a ideia do esgoto coletor de ramificações invisíveis e radiantes conclui a representação mecânica e orgânica da alimentação urbana, a do trabalho interior garantida pelos fluxos" (Vigarello, 2001, p. 201). 
Se a situação ficava resolvida para as escolas do Barreiro, o mesmo não se passava no resto do concelho. E aqui entende-se, apenas, as escolas do Lavradio, porque as restantes estavam instaladas em edifícios alugados, desconhecendo-se por isso o sistema de sanitários que teriam e como se processava o seu esvaziamento. Os pedidos para despejo das fossas quase sempre revestiam um caráter de urgência e é fácil imaginar o porquê: por exemplo, no início de 1919, a professora do Lavradio enviou um ofício à Câmara pedindo para que fosse despejada com urgência a fossa daquela escola, "por não poder fazer uso das retretes" (AMB, 29 jan., 1919). O poder local reconhecia, por vezes, os inconvenientes que a falta de limpeza das escolas ocasionava para a saúde pública, como se constata pela preocupação demonstrada nos primeiros tempos de mandato de um executivo camarário, em Outubro de 1923:

O presidente informou que sendo a limpeza das escolas oficiais encargo obrigatório desta Câmara, se costuma incluir no orçamento da Junta Escolar uma determinada verba para aquele serviço, que por ser insuficiente, dá origem a que a escola não seja convenientemente limpa com grave perigo para as centenas de crianças que frequentam as escolas. Tem esta Câmara que obviar a este inconveniente, em nome da higiene e da saúde pública e por isso lembra que esta Câmara tome o encargo de efetuar a limpeza das escolas. (AMB, 3 out., de 1923)

Atente-se, agora, no que se passava nas instalações do Asilo D. Pedro V, que sempre funcionou, apenas, como externato, situado no centro da vila. Relativamente às dependências sanitárias, verificou-se que Ihes foi votada muito pouca atenção ao longo dos tempos, atendendo ao escasso número de registos que lhes fizesse referência: apenas se encontrou, no mês de abril de 1862, o registo da despesa de $\$ 960$ réis com a "limpeza das latrinas" (ADPV, Conta das despezas 1862-1864) e, num outro livro, mencionada a palavra "privada" (ADPV, Livro das despezas 1874-1897). Todavia, tem de se ressalvar que, na época, a existência de casa de banho seria uma excepção nas casas portuguesas, e mesmo para a esmagadora maioria dos arquitetos, o compartimento das instalações sanitárias dentro de casa seria, no primeiro quartel do século 20, uma divisão ainda supérflua (Cabido, 1994). Com o avançar do século 20, essa zona começa a ser objeto de cuidados por parte dos dirigentes do Asilo que sentem que há necessidade de proceder a melhoramentos significativos:

Por ser anti-higienica a barraca destinada à retrete das crianças asiladas, cuja disposição as forçava a uma completa promiscuidade, providenciou em tempos esta Direção para se acabar com tal inconveniente, que constituia uma absoluta vergonha, resolução que há pouco se satisfez com a construção duma barraca mais ampla e feita em condições que, sem aqueles inconvenientes, apresenta um aspeto completamente agradável. (ADPV, Livro de actas da direcção 1921 a 1926, n. II, 2 de jun., 1924)

No que concerne à limpeza do edifício, e tendo como ponto de referência o Regulamento Interno para os Alumnos Externos do Asylo D. Pedro V do Campo Grande de 1862, vê-se que estas questões da higiene não eram menosprezadas: "Convindo que [...] se conserve a maior limpeza, haverá por isso todo o cuidado que as bacias das latrinas sejam lavadas durante o dia tantas vezes quantas se julguem necessarias" ( $p$. 11), "aos sábados, depois do jantar, as crianças retiram para suas casas, a fim de ter 
lugar a lavagem do edificio" (Ibid.), sendo escolhidas, de entre as alunas mais velhas, quatro por semana e por turno, para fazerem o serviço da casa, juntamente com a criada. Atendendo a estes normativos que vigoravam num edifício similar e não havendo mais dados, infere-se que a limpeza do edifício do Asilo do Barreiro também estaria a cargo da serviçal mas aos sábados seria ajudada pelas alunas mais velhas: "estavam presentes só 21 crianças por ser véspera de festa, faziam contas e limpavam a casa por ser sábado o dia da limpeza" (ADPV, Registo das Senhoras Directoras e Inspectoras, 9 set. 1882). Durante a semana, caberia à criada ter tudo limpo às 8 h e meia (Ibid., 12 jan., 1883). Nas despesas mensais, entre 1874 e 1897, há sempre o registo de verbas gastas com "lavagem de roupas" e "limpeza de casa e quintal" (ADPV, Livro das despezas 18741897); tais despesas, contudo, deveriam ser uma constante ao longo dos tempos naquela instituição, porque encontram-se registos em 1924 que atestam que a limpeza do asilo, e a lavagem da roupa das asiladas continuaria a estar a cargo de uma serviçal (ADPV, n. II, 2 jun., 1924).

No tocante às questões da higiene pessoal, mais concretamente à higiene capilar dos alunos, constata-se que andar de cabelo cortado era um imperativo da instituição, muito provavelmente como medida terapêutica e preventiva de problemas de pediculose, para além de que "la coupe des cheveux correspondait non seulement à un sacrifice, mais à une reddition: c'était la renonciation - volontaire ou imposée - aux vertus, aux prérogatives, finalement à sa propre personalité" (Chevaliern ; Gheerbrant, 1973, p. 366). No entanto, esta prática não seria muito bem aceite por todos, porque no Livro de matrículas 1855-1955 há vários registos de saída de alunos do Asilo, todos antes de 1891: "por não querer cortar o cabelo", "por os pais não the quererem cortar o cabello" e "porque a mãe a achava já muito crescida para ter o cabelo cortado!!". Desta atitude de recusa do cabelo cortado, quer seja por parte dos alunos ou dos pais, não se pode dissociar o significado que aquela parte do corpo assume, porque "la coupe et la disposition de la chevelure ont toujours été un élément déterminant non seulement de la personnalité, mais aussi d'une fonction sociale ou spirituelle, individuelle ou collective" (Ibid., p. 367).

A normativa do corte de cabelo perduraria no tempo, uma vez que, em 30 de junho de 1925, há assentamento da despesa de $46 \$ 05$ com "cortes de cabelo de crianças asiladas" e em 10 de dezembro desse mesmo ano gastaram-se $34 \$ 50$ pelo "corte de cabelo aos alunos" (ADPV, f. 55 e f. 61). Em suma, pode-se dizer que o espaço do Asilo assumiu-se sempre como um espaço a defender da doença, por meio de preceitos higiénicos simples, adequados às épocas que o atravessaram, que se aplicavam às pessoas e ao edifício. De forma abreviada, poder-se-ia dizer que água, sabão e tesoura eram as armas da luta.

Se, em cada escola, a vigilância pelos preceitos higiénicos era incumbência do professor, a nível concelhio tal tarefa estaria adstrita ao médico escolar, como atrás se referenciou, e, quando não o houvesse, ao subdelegado de saúde. Assim, a fim de dar cumprimento a uma medida legislativa, em início de setembro de 1919, em reunião da Comissão Executiva da Câmara Municipal tomar-se-ia conhecimento de uma circular da Inspeção Geral de Sanidade Escolar, datada de 28 de agosto daquele ano, pedindo para ser aberto concurso documental para um médico escolar, de entre os médicos municipais (AMB, 10 de set., 1919). 
O resultado daquele concurso deveria ser posteriormente enviado àquela entidade, a fim de que a mesma pudesse proceder conforme determinavam os regulamentos em vigor para com o funcionário escolhido pela Câmara Municipal. Esta deliberou que informaria a Inspeção-Geral de Sanidade Escolar participando-lhe que a inspeção sanitária das escolas estava a cargo do subdelegado de saúde do concelho, contudo, não parece que o tenha feito logo de seguida, porque, na ata de 31 de dezembro de 1919, há registo de pedido de resposta àquela circular, tendo-se resolvido indicar o médico dr. Francisco Dias Nogueira para aquele lugar, "por ser o médico do partido municipal o que apresentou provas no seu concurso" (AMB). Se este médico desempenhou as novas tarefas que a legislação lhe impunha pela assunção do cargo, não se sabe, mas infere-se que, a exemplo de tantas outras coisas legisladas, esta medida foi apenas mais uma para ficar somente no papel.

As questões da saúde, e mais concretamente da higiene dos espaços, passavam também pelo mobiliário escolar. O espaço que cada aluno tinha na sala acabava por se limitar ao lugar que ocupava sentado, reduzindo-lhe, assim, a possibilidade de movimento, pelo que, a partir do mobiliário existente nas escolas para os alunos, surgiram posturas que estes adquiriram com o uso quotidiano do mesmo. Adolfo Lima critica mesmo a falta de mobilidade do aluno dentro da sala de aula, numa semelhança muito interessante com a visão de Foucault da escola:

A permanência da criança durante uma, duas e quatro horas em cada dia, assentada num banco, não the sendo permitido falar, rir, quebra-lhe a natural e necessária expansão das suas energias. Semelhante regime criaIhe hábitos indolentes, fá-la preguiçosa e apaga-lhe o espírito, lançando-a numa apatia mórbida. A escola converte-se, pelo silêncio embrutecedor, num convento; pela disciplina degradante, numa caserna; pela falta de liberdade, numa prisão! É o medo que impera. É lúgubre. É um lugar de tortura que a criança natural e justificadamente odeia. (Lima, 1914, p. 68)

Para além da posição do aluno, também a sua localização na aula era um aspeto a que se atribuía pouca importância e que era determinante, muitas vezes, do insucesso nos estudos: "na escola arrumam-nas para um lugar ao acaso, sem cuidarem saber se as crianças vêem, ouvem ou se se podem fazer ouvir; o resultado é a criança fatigar-se com esforço que fez na aplicação do sentido defeituoso, seguindo-se à fadiga o desinteresse" (Ferrão, 1913, p. 81). Um artigo publicado na Revista de Educação e Ensino de 1889 alertava para estes perigos: "na transmissão educativa transformada ao impulso da civilização moderna há, como consequência de grandes causas de erro, alterações patológicas individuais que se podem grupar em duas classes: - alterações anatómicas e alterações funcionais" (Ferreira, 1889, p. 248). Relativamente às alterações anatómicas explicava que

o tipo normal especifico do homem atual sofre, em virtude da adaptação escolar, um desvio bastante notável e importante, no ponto de vista antropológico que compreende o individuo, a espécie e as sociedades. A alteração d'este tipo é o resultado das deformações a que o individuo é sujeito durante a atividade escolar. Estas deformações são o produto das posições viciosas que tomam os alunos ou que lhes fazem tomar no exercicio quotidiano de desenvolvimento intelectual e de apreciação cientifica. (lbid., p. 248) 
As mais vulgares deformações anatómicas resultantes da atividade escolar eram desvios da coluna vertebral: a cifose "produzida pelas atitudes demoradas, com o dorso curvado, lendo, escrevendo ou costurando, e devida, em parte, à necessidade creada pela miopia de inclinar muito o tronco para aproximar os olhos do trabalho em execução" (Ferreira, 1889, p. 249); a lordose, "incurvação que tem mais geralmente lugar nas mulheres e que, como deformação escolar tem a sua etiologia na atitude forçada a que são obrigadas as alunas para se manterem direitas em assentos sem espaldar" (Ibid., p. 249); e a escoliose "produz-se, em geral, dos 6 aos 14 anos e é mais frequente nas raparigas que nos rapazes, menos acomodaticios à manutenção das posições e mais prontos em modificá-las" (Ibid., p. 250). Deste modo, a escola era vista como um espaço de degeneração que punha em causa a saúde das novas gerações: "e que fatalidade para um país e para uma sociedade se a escola é como uma mina que deteriora a constituição de uma parte importante dos seus membros, num trabalho inglório e improdutivo!" (Ibid., p. 253).

O grande problema residia no facto de o aluno ter de se adaptar a um meio de vida diferente do normal e ficar sujeito a atitudes antinaturais por períodos prolongados: "submetido o indivíduo na escola às posições viciosas mais ou menos conservadas, contido ou contrariado nos seus impulsos juvenis, perde essa vivacidade carateristica e necessária das crianças, quebra-se o equilibrio funcional" (Ferreira, 1889, p. 253). Para além deste problema, havia outro: "a miopia é o triste apanágio dos que estudam, como de todos os que trabalham tendo a visão acomodada para muito perto" (Ibid., p. 255).

Com vista a minimizar todos estes problemas de saúde, tomaram-se várias medidas: para diminuir as deformações da coluna produziram-se "melhoramentos nas escolas, tanto na mobilia, como no regulamento das horas de estudo e na introdução da ginástica e de recreações necessárias e utilissimas" (Ibid., p. 256), mas para a miopia, uma das perturbações anatómicas considerada por alguns "a doença escolar por excelência" (Ibid., p. 255), não se havia ainda encontrado uma solução, porque os programas obrigavam o aluno a um excesso de aplicação, não só na escola, mas também em casa, que muitas vezes se fazia sob condições deficientes de luminosidade. Deste modo, as crianças, ao apropriaram-se do espaço físico compactado que lhes era determinado e com o tempo prolongado que aí permaneciam, acabavam por habituar-se a determinadas posições, ou seja, o aprisionamento em espaços fechados acabaria por agir de forma nefasta sobre o corpo.

\section{Notas finais}

A partir do final do século 19, a racionalidade médica movimenta-se recobrindo o espaço íntimo da casa e da família, e como a escolarização se tornou um fenómeno fundamental na construção de países desenvolvidos e na afirmação da modernidade ocidental, a escola viu-se também alvo da atenção dos médicos que preconizavam uma estratégia preventiva e profilática. Contudo, o discurso médico-pedagógico serviu, principalmente, para legitimar e conferir uma racionalidade científica aos princípios de organização impostos por razões administrativas, uma vez que a sua força de intervenção nas práticas pedagógicas era diminuta. 
A escola e os alunos passaram a ser objeto de uma atenção particular pela medicina e pelos movimentos higienistas. As condições de salubridade e de higiene da vida corrente invadem a escola: reclama-se uma arquitetura própria e materiais de construção adequados, a que se aliam a funcionalidade e infraestruturas específicas, volumetria e arejamento de acordo com padrões estandardizados, bem como a introdução de mobiliário específico exclusivo desse espaço: as carteiras. Mas a lista não termina aqui: exige-se à escola que divulgue novos comportamentos, que ensine novas noções, que inculque formas de viver higiénicas e que verifique a saúde dos seus alunos, de forma a prevenir contágios, parasitas e doenças. Em suma, impõe-se à escola o ensino de uma higiene protetora e a organização escolar é reformulada de acordo com a ciência médicohigiénica.

\section{Referências}

AMB. Livro de actas das sessões da Comissão Administrativa da Câmara Municipal do Concelho do Barreiro. 26/11/1919 a 8/8/1921.

BETTENCOURT, Nicolau. Prevenção contra as doenças contagiosas. CONGRESSO PEDAGÓGICO, 3, 1912, Lisboa. Anais ... Lisboa: Liga Nacional de Instrução, 1912, p. 137-142.

BOLETIM DA DIRECÇÃO GERAL DE INSTRUCÇÃO PUBLICA. Anno de 1902. Anno I. Fasc. I-V. Janeiro-Maio 1902. Lisboa: Imprensa Nacional, 1903.

BOTO, Carlota. A escola primária como rito de passagem: ler, escrever, contar e se comportar. Coimbra: Imprensa da Universidade de Coimbra, 2012.

CABIDO, José Jacob. Reflexões sobre o interior doméstico: as mentalidades e os espaços. Lisboa: UTL, 1994. 381f. Tese (doutorado em Arquitetura de Interiores). Faculdade de Arquitetura, Universidade Técnica de Lisboa.

CÂMARA MUNICIPAL DO BARREIRO. Divisão de Obras, projecto de fóssa, systema mouras applicado ás retretes da escola do sexo masculino e feminino na Villa do Barreiro, 30 de abril de 1902.

CHEVALIER, Jean; GHEERBRANT, Alain. Dictionnaire des symboles: mythes, rêves, coutumes, gestes, formes, figures, couleurs, nombres. Dixième édition, v. 1. Paris: Seghers, 1973.

COLLECÇÃO de providencias sobre o material das escolas primarias, creação de bibliothecas populares e organisação de commissões promotoras de ensino. Lisboa: Imprensa Nacional, 1876.

DOCUMENTOS variados e manuscritos do Asilo D. Pedro V do Barreiro (ADPV).

ÉCO DO BARREIRO. Quinzenário independente, defensor dos interesses do Concelho do Barreiro. Ano II, n. 33. Barreiro, 15 de março de 1925.

FERRÃO, António. Surmènage escolar. In: Liga Nacional de Instrução. CONGRESSO PEDAGÓGICO, 3, 1912, Lisboa. Anais ... Lisboa: Liga Nacional de Instrução, 1912, p. 41130.

FERREIRA, António Gomes. Higiene e controlo médico da infância e da escola. Cadernos Cedes, v. 23, n. 59, 2003, p. 9-24. 
FERREIRA, António Gomes. Modernidade, higiene e controle médico da infância e da escola. In: ALMEIDA, Malu (org.). Escola e modernidade: saberes, instituições e práticas. Campinas: Alínea, 2004, p. 97-111.

FERREIRA, J. B. As deformações escolares. In: Revista de Educação e Ensino. Volume IV. Lisboa: Imprensa de Lucas Evangelista Torres, 1889, p. 248-257.

FERREIRA, Pedro José. Educação física, a gimnástica e os jogos ao ar livre: quando e como devem ser ministrados. In: Liga Nacional de Instrução. CONGRESSO PEDAGÓGICO, 3, 1912, Lisboa. Anais ... Lisboa: Imprensa Nacional, 1912, p. 157-164.

GONDRA, José. Homo hygienicus: educação, higiene e a reinvenção do homem. Cadernos Cedes, v. 23, n. 59, 2003, p. 25-38.

LIMA, Adolfo. Educação e ensino. Lisboa: Guimarães, 1914.

MINISTÉRIO DOS NEGÓCIOS DO REINO, Direcção Geral de Instrucção Primaria, 1. ${ }^{a}$ Repartição. Portaria de 5 de abril de 1910. In: Regulamentação da qualificação do serviço annual dos inspectores, sub-inspectores e professores de instrucção primaria. Lisboa: Imprensa Nacional, 1910.

NAZARETH, Pedro Dória. O estudo da hygiene no ensino primário e normal. Liga Nacional de Instrucção. CONGRESSO PEDAGÓGICO DE INSTRUCÇÃO PRIMARIA E POPULAR, 1, 1908, Lisboa. Anais ... Lisboa: Imprensa Nacional, 1909.

PEREIRA, Armando dos Santos Pinto. A higiene nas escolas primárias do Porto. Dissertação inaugural apresentada à Faculdade de Medicina do Porto. Porto: Empresa Gráfica A Universal, 1913.

REFORMAS DO ENSINO EM PORTUGAL 1900-1910. Tomo I, v. IV, $1^{a}$ parte. Lisboa: Ministério da Educação, 1996.

REGULAMENTO interno para os alumnos externos do Asylo D. Pedro V para a Infância desvalida do Campo Grande. Lisboa: Imprensa Nacional, 1862.

REVISTA ESCOLAR PORTUGUEZA. Anno I, n. 2, 15 de março de 1884.

ROCHA, Artur Fernando. Doenças contraídas na escola e seus remédios. CONGRESSO PEDAGÓGICO, 3, 1912, Lisboa. Anais ... Lisboa: Liga Nacional de Instrução, 1912, p. 131-136.

VIGARELLO, Georges. História das práticas de saúde: a saúde e a doença desde a Idade Média. Lisboa: Notícias, 2001.

MARIA MANUELA RODRIGUES é doutora em Ciências da Educação pela Universidade Nova de Lisboa e investigadora no Instituto de Educação da Universidade de Lisboa.

Endereço Postal: Rua do Bom Sucesso, n. 20 - 2835-327 - Lavradio - Portugal.

E-mail: mmpfrodrigues@hotmail.com.

Recebido em 31 de março de 2013.

Aceito em 11 de setembro de 2013. 